\title{
TU/e EN⿴HONE

\section{Performance analysis of aromatic adsorptive resins for the effective removal of furan derivatives from glucose}

\section{Citation for published version (APA):}

IJzer, A. C., Vriezekolk, E., Rolevink, E., \& Nijmeijer, K. (2015). Performance analysis of aromatic adsorptive resins for the effective removal of furan derivatives from glucose. Journal of Chemical Technology and Biotechnology, 90(1), 101-109. https://doi.org/10.1002/jctb.4294

DOI:

10.1002/jctb.4294

Document status and date:

Published: 01/01/2015

\section{Document Version:}

Publisher's PDF, also known as Version of Record (includes final page, issue and volume numbers)

\section{Please check the document version of this publication:}

- A submitted manuscript is the version of the article upon submission and before peer-review. There can be important differences between the submitted version and the official published version of record. People interested in the research are advised to contact the author for the final version of the publication, or visit the $\mathrm{DOI}$ to the publisher's website.

- The final author version and the galley proof are versions of the publication after peer review.

- The final published version features the final layout of the paper including the volume, issue and page numbers.

Link to publication

\section{General rights}

Copyright and moral rights for the publications made accessible in the public portal are retained by the authors and/or other copyright owners and it is a condition of accessing publications that users recognise and abide by the legal requirements associated with these rights.

- Users may download and print one copy of any publication from the public portal for the purpose of private study or research.

- You may not further distribute the material or use it for any profit-making activity or commercial gain

- You may freely distribute the URL identifying the publication in the public portal.

If the publication is distributed under the terms of Article 25fa of the Dutch Copyright Act, indicated by the "Taverne" license above, please follow below link for the End User Agreement:

www.tue.nl/taverne

Take down policy

If you believe that this document breaches copyright please contact us at:

openaccess@tue.nl

providing details and we will investigate your claim. 


\title{
Performance analysis of aromatic adsorptive resins for the effective removal of furan derivatives from glucose
}

\author{
Anne Corine IJzer, Erik Vriezekolk, Erik Rolevink and Kitty Nijmeijer*
}

\begin{abstract}
BACKGROUND: Many countries have set goals to replace conventional energy sources with renewable energy sources. This has led to investigations into the use of lignocellulosic biomass as a feedstock for renewable fuels and base chemicals. Unfortunately hydrolysation of this biomass introduces impurities that are toxic to the fermentation bacteria. This study aims to find the key adsorber properties for the separation of toxic 5-hydroxymethylfurfural (HMF) from glucose.

RESULTS: Batch adsorption experiments on styrene based (anion exchange) adsorbers showed that a high surface area is a key property for effective HMF adsorption. Introduction of polar groups in the form of anion exchange groups appears to increase the HMF-affinity of the resin material, unfortunately these groups also introduce affinity for glucose. Competitive adsorption studies of HMF and glucose showed that glucose does not affect HMF adsorption in any of the resins.

CONCLUSION: Furan derivatives can be removed from water and sugar solutions with styrene based (anion exchange) polymeric resins. For efficient removal, a high surface area of the resin is a key property. Dowex Optipore L-493 shows the best specific HMF adsorption and no specificity for glucose, which makes it an excellent adsorber for HMF removal from hydrolysate for the fermentation of glucose.
\end{abstract}

C) $\mathbf{2 0 1 3}$ Society of Chemical Industry

Keywords: aromatic resin; adsorption; HMF; sugars; biorefinery

\section{INTRODUCTION}

Many countries have set goals to replace conventional energy sources with renewable energy sources, because of growing energy demands, greenhouse emissions and depleting oil and natural gas resources. ${ }^{1}$ This has led to investigations into the use of biomass as a feedstock for renewable fuels and base chemicals. ${ }^{2}$ Biofuels derived from lignocellulosic biomass could fulfill a large part of the demand for biobased fuels responsibly. ${ }^{3}$ Lignocellulosic biomass not only includes dedicated energy crops but also agricultural residues (corn stover and sugarcane bagasse), wood residues and municipal paper waste. ${ }^{4}$ Lignocellulosic biomass is biomass of plants and consists of cellulose, hemicellulose and lignin. Cellulose and hemicellulose are carbohydrate polymers that, once removed from the lignin, can be hydrolysed into sugars (glucose and xylose). After removal of the impurities induced by the hydrolysation, these sugars can serve as a feedstock to produce ethanol, lactic acid and other valuable chemicals.

Sulfuric acid is a well known catalyst for the hydrolysation of cellulose and hemicellulose in biomass to sugars. ${ }^{4}$ Unfortunately this can lead to formation of byproducts (acetic acid) and to degradation of lignin to phenolic compounds and of the sugars to furfural (from xylose) and 5-hydroxymethylfurfural (HMF) (from glucose). ${ }^{3}$ These components are toxic for the bacteria in the downstream fermentation process and need to be removed before further processing. Several authors showed that these toxins can be removed by adsorption. Polymeric adsorbers, ${ }^{5-8}$ cat- and anion exchange resins (weak and strong), ${ }^{2,9-11}$ zeolites $^{1}$ and activated carbon $^{11-13}$ have shown to remove these toxins. Because of regeneration, stability and capacity, polymeric adsorbers (resins), with and without ion exchange groups, are considered most promising for adsorption of these toxins. ${ }^{4,14}$

Acids and phenolic compounds adsorb best on anion exchange resins. ${ }^{15}$ However, research on furan adsorption is inconclusive on the best adsorption resin for furan adsorption. Dowex recommends the use of a styrene-divinylbenzene (DVB) based weak base ion exchange resin (Optipore SD-2) for the removal of the furan 5hydroxylethylfurfural (HMF). ${ }^{16}$ While literature has shown good results for HMF removal with anion exchange resins, $9,15,17$ it is probably the non-polar styrene-DVB matrix that is responsible for furan adsorption. ${ }^{5,14}$ Some authors have compared the adsorption of furans on weak anion exchange resins, strong anion exchange resins and polymeric adsorbers. ${ }^{9,15}$ Unfortunately the matrix of the different resins varied (acrylic or styrene based) making it difficult to relate the adsorption performance purely to the presence or absence of ion exchange groups. Fargues et al. ${ }^{14}$ made a thorough comparison based on single component isotherms and breakthrough curves of ion exchange (weak and strong) resins

Correspondence to: Kitty Nijmeijer, Membrane Science \& Technology, Mesa + Institute for Nanotechnology, University of Twente, P.O. Box 217, 7500 AE Enschede, The Netherlands.E-mail:d.c.nijmeijer@utwente.nl

Membrane Science \& Technology, Mesa + Institute for Nanotechnology, University of Twente, P.O. Box 217, 7500, AE, Enschede, The Netherlands 


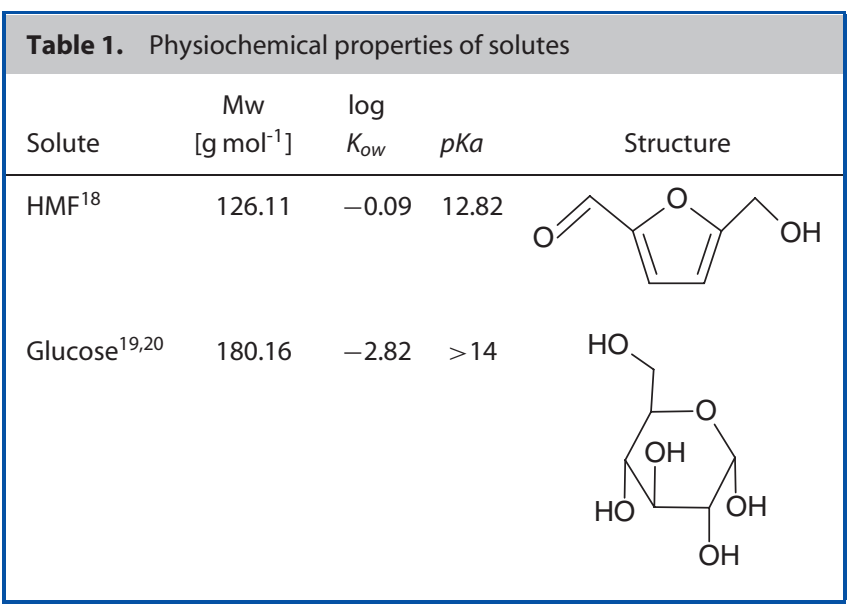

with polymeric adsorbers, all with styrene-DVB based matrices. Although the good furan adsorption on the styrene-DVB resin is consistent with the findings of others, $5,6,15$ the low adsorption of furans on styrene based anion exchange resins is not consistent with the findings of others. ${ }^{2,9,15}$ Other research on this subject only examines the effect of adding different resins to the hydrolysate on the effectiveness of the fermentation. ${ }^{2,8,9}$ Although this leads to a selection of resins that improve fermentation production, it does not provide further insight into the adsorption mechanisms involved (e.g. specificity of adsorption of toxin, competitive adsorption, sugar loss) and therefore design of specific resins for this rapidly increasing industry is difficult. Although literature has shown that a styrene based resin is a good furan adsorber, the addition of polar anion exchange groups in the resin on the furan adsorption is not well understood.

This study aims to provide more insight to the adsorption mechanism of furans for the removal of furans from sugar on commercial styrene-DVB based resins. In contrast to previous research, ${ }^{9,15}$ this study investigates resins with a similar matrix. Two styrene based resins and three different styrene based anion exchange resins are investigated. Insight to the adsorption mechanism is obtained by relating the adsorption isotherms of HMF and glucose (pure and competitive) to the physical (BET surface area, pore size, pore volume, swelling and water uptake) and chemical properties (none, weak or strong anion exchange groups) of the resins. HMF and glucose are chosen as model components. HMF represents a large class of furan toxins and is therefore chosen as a model component for furans, while glucose represents a large class of sugars and is therefore chosen as model component for sugar (see Table 1).

\section{MATERIALS AND METHODS Materials}

The resins Amberlite XAD4 (XAD4), Dowex Optipore L-493 (Optipore), Lewatit MP 62 (MP62), Lewatit M500 (M500) and Reillex HP (PVP) were purchased from Sigma Aldrich (Table 2). All resins have a styrene matrix crosslinked with divinylbenzene (DVB). The matrix of all resins therefore fully consists of polar aromatic rings. The resins MP62, PVP and M500, contain the following alkaline functional groups attached to the matrix: tertiary amine, 4-vinylpyridine and quaternary amine, respectively. All resins are macroporous, except for Lewatit M500, which is a gel type resin. 5-hydroxymethylfurfural (HMF), glucose, sulfuric acid $\left(\mathrm{H}_{2} \mathrm{SO}_{4}\right)$ and sodium hydroxide $(\mathrm{NaOH})$ were obtained from Sigma Aldrich.
XAD4 and Optipore are polymeric adsorbents without functional groups. They have the same chemical structure, a styrene based matrix crosslinked with DVB, but they have different physical properties (e.g. surface area and pore size). They are selected to determine the HMF and glucose adsorption capacity of the styrene-DVB matrix. Because they have different surface areas, the adsorption capacity can also be related to the surface area. HMF is more apolar than glucose and it is therefore expected that it will adsorb on the apolar styrene resin while the polar glucose is less or not adsorbed. This is also seen by the relative lower log octanol/water partition coefficient (log $\mathrm{K}_{\mathrm{ow}}$ ) of glucose compared with HMF, which represents the solubility in octanol relative to the solubility in water (Table 1). MP62 and PVP are weak base anion exchange resins and M500 is a strong base anion exchange resin. These resins have the same matrix as XAD4 and Optipore, but with different alkaline functional groups (tertiary amine, vinylpyridine and quartinary amine, respectively). These polar alkaline groups can alter the affinity for HMF and/or glucose of the adsorbent, as well as the swelling in water of the resin due to the introduction of the polar groups.

To remove impurities present in the resins, all resins were rinsed with MilliQ water prior to use until no impurities were visible by UV-vis (200-400 nm). M500 is received in the $\mathrm{Cl}^{-}$form (M500(Cl-)) and is also brought into the $\mathrm{OH}^{-}$form (M500 $\left(\mathrm{OH}^{-}\right) .10 \mathrm{~g} \mathrm{M} 500\left(\mathrm{Cl}^{-}\right)$ was rinsed with a $500 \mathrm{~mL} 1 \mathrm{~mol} \mathrm{~L}^{-1}$ sodium hydroxide $(\mathrm{NaOH})$ solution $(24 \mathrm{~h})$. The solution was refreshed four times to ensure complete exchange of $\mathrm{Cl}^{-}$to $\mathrm{OH}^{-}$. The resins were rinsed with MilliQ water to remove excess $\mathrm{NaOH}(24 \mathrm{~h})$.

\section{Resin properties}

\section{Particle size}

The particle size distribution of all resins were measured by dynamic light scattering (DLS) at $25^{\circ} \mathrm{C}$ in a Malvern Zetasizer HS3000. A nominal $5 \mathrm{~mW}$ Helium Neon laser with a wavelength of $633 \mathrm{~nm}$ was used to measure the particle size distributions at angles of $12^{\circ}$ and $90^{\circ}$. The correlograms were analyzed using the CONTIN algorithm.

\section{Nitrogen adsorption}

The specific surface area (BET), pore size and pore volume were measured using nitrogen adsorption at $-195.8^{\circ} \mathrm{C}$ with a Micromeritics Tristar 3000. ${ }^{27}$ Before the measurement the resins were heated overnight to $80^{\circ} \mathrm{C}$ under nitrogen flow.

\section{Volume change and water uptake}

The volume change and water uptake of the resins under the influence of water was investigated. The volume of the resins was measured after the resins were equilibrated in water ( $24 \mathrm{~h}$ ). The resins were subsequently removed from the excess water by filtration and their mass was determined. The mass and volume were measured again after the resins were dried in a vacuum oven at $80^{\circ} \mathrm{C}(24 \mathrm{~h})$. This mass was used to determine the swelling and the water uptake with the following equations:

$$
S=\frac{V_{w e t}-V_{d r y}}{m_{d r y}}
$$

with $S$ the volume change per gram dry resin $\left[\mathrm{mL} \mathrm{g}^{-1}\right.$ dry resin $], V_{\text {wet }}$ and $V_{d r y}$ the volume $\mathrm{mL}$ of the wet and dry resin, respectively, and 
Table 2. Resin specifications

\begin{tabular}{|c|c|c|c|c|c|}
\hline Resin & Matrix & Type & $\begin{array}{l}\text { Functional } \\
\text { group }\end{array}$ & $\begin{array}{c}\text { lon exchange } \\
\text { capacity [min. eq } \mathrm{L}^{-1} \text { ] }\end{array}$ & $\begin{array}{l}\text { Surface area } \\
\qquad\left[\mathrm{m}^{2} \mathrm{~g}^{-1}\right]\end{array}$ \\
\hline XAD4 ${ }^{21}$ & Poly(styrene- DVB) & Adsorbent & None & - & $>750$ \\
\hline Optipore 22 & Poly(styrene- DVB*) & Adsorbent & None & - & $>1100$ \\
\hline$M P 62^{23}$ & Poly(styrene- DVB) & Weak base anion exchanger & Tertiary amine & 1.7 & n.a. \\
\hline PVP24 & Poly(styrene- DVB) & Weak base anion exchanger & Vinyl pyridine & 1.7 & n.a. \\
\hline M500 $\left(\mathrm{Cl}^{-}\right)^{25}$ & Poly(styrene- DVB) & Strong base anion exchanger & Quaternary amine & 1.3 & n.a. \\
\hline
\end{tabular}

$m_{d r y}$ the mass of the dry resin $\left[g_{d r y}\right.$ resin $]$.

$$
W U=\frac{\left(m_{\text {wet }}-m_{d r y}\right)}{m_{d r y} \cdot \rho_{H 2 O}}
$$

with $W U$ the water uptake per gram dry resin $\left[\mathrm{mL} \mathrm{g}^{-1}\right.$ dry resin $], m_{\text {wet }}$ and $m_{d r y}$ the mass [g] of the wet and dry resin, respectively, and $\rho_{\mathrm{H} 2 \mathrm{O}}$ the density of water $\left[\mathrm{g} \mathrm{mL}^{-1}\right]$.

\section{Adsorption isotherms}

HMF and glucose adsorption isotherms were determined to investigate the capacity, affinity and selectivity of the different resins (XAD4, Optipore, MP62, M500 $\left(\mathrm{Cl}^{-}, \mathrm{OH}^{-}\right.$) and PVP) for HMF and glucose. Adsorption behavior of the resins was studied by measuring the following adsorption isotherms:

1. single HMF adsorption (low and high HMF concentrations);

2. single glucose adsorption;

3. competitive HMF/glucose adsorption;

4. HMF adsorption as function of temperature.

The maximum adsorption capacity was determined from the HMF adsorption isotherms at high HMF concentrations in water (1000-20 $\left.000 \mathrm{mg} \mathrm{L}^{-1}\right)$. The HMF binding strength and adsorption capacity of the resins was investigated at low HMF concentrations $\left(1-30 \mathrm{mg} \mathrm{L}^{-1}\right)$ in water since this gives more information on the affinity of the materials for HMF. Furthermore this is the concentration range of the targeted industrial processes. Glucose adsorption of the resins was investigated with glucose concentrations ranging from $1-100 \mathrm{~g} \mathrm{~L}^{-1}$ in water.

Competitive adsorption of HMF and glucose was studied by measuring HMF adsorption in a glucose solution $\left(100 \mathrm{~g} \mathrm{~L}^{-1}\right)$. HMF adsorption from a glucose solution was determined at low (1-30 $\left.\mathrm{mg} \mathrm{L}^{-1}\right)$ concentrations for Optipore and XAD4 and due to analysis limitations, at high HMF concentrations (1000-20 $000 \mathrm{mg} \mathrm{L}^{-1}$ ) for the other resins. All these experiments were performed at $20^{\circ} \mathrm{C}$.

Additionally the effect of temperature on the HMF adsorption capacity of Optipore was studied at 20 and $60^{\circ} \mathrm{C}$ and $\mathrm{HMF}$ concentrations from $1000-20000 \mathrm{mg} \mathrm{L}^{-1}$ in water.

In general $25 \mathrm{~mL}$ of solution was added to $0.3 \mathrm{~g}$ wet resin in a $30 \mathrm{ml}$ flask. The solutions were equilibrated for $48 \mathrm{~h}$ (MP 62) or $24 \mathrm{~h}$ (all other resins) in a thermostatic shaking bath $\left(20^{\circ} \mathrm{C}\right.$ or $60^{\circ} \mathrm{C}$ ). The equilibration time for the solute adsorption was determined in separate experiments (not shown in this article). After the equilibration time, the equilibrium concentration was determined using HPLC.

HMF and glucose concentrations were determined with a Waters HPLC with a 515 pump, a 2487 dual $\lambda$ adsorbance detector and
Millenium $^{32}$ (version 3.20) software. Analysis was carried out using the column Resex ROA-organic acid $300 \times 7.8 \mathrm{~mm}$ (Phenomenex). The mobile phase was $0.005 \mathrm{~mol} \mathrm{~L}^{-1} \mathrm{H}_{2} \mathrm{SO}_{4}$. The column was operated at $90{ }^{\circ} \mathrm{C}$ with a flow rate of $0.3 \mathrm{~mL} \mathrm{~min}^{-1}$ of the mobile phase. Peak detection was performed with UV at $284 \mathrm{~nm}$ (HMF) and $205 \mathrm{~nm}$ (glucose).

At high concentrations the adsorption isotherms are described by Langmuir sorption: ${ }^{28}$

$$
q=\frac{b \cdot c_{e q} \cdot q_{\max }}{1+b \cdot c_{e q}}
$$

with $q\left[\mathrm{~g}_{\text {solute }} / \mathrm{g}_{\text {resin }}\right]$ the adsorption capacity at equilibrium concentration $c_{e q}\left[g_{\text {solute }} \mathrm{L}^{-1}\right], b \quad\left[\mathrm{Lg}^{-1}\right.$ solute $]$ the Langmuir equilibrium constant that indicates the energy of adsorption, which increases when the strength of the adsorption bond increases, and $q_{\max }\left[g_{\text {solute }} \mathrm{g}^{-1}\right.$ resin $]$ is the maximum adsorption capacity of the resin.

At low concentrations the adsorption isotherms are correlated using the Freundlich equation: ${ }^{28}$

$$
q=K \cdot c_{e q}^{1 / n}
$$

with $q$ [mg solute $\left.\mathrm{g}^{-1}\right]$ the adsorption capacity at equilibrium concentration, $c_{e q}\left[\mathrm{mg}_{\text {solute }} \mathrm{L}^{-1}\right], K\left[\mathrm{Lg}^{-1}\right.$ resin $]$ the freundlich equilibrium constant that indicates the maximum adsorption capacity, and $1 / n$ the constant measuring the strength of adsorption. A lower $1 / n$ indicates a higher adsorption strength.

\section{RESULTS AND DISCUSSION}

\section{Resin analysis}

The particle size, BET surface area, mean pore size and volume, water uptake and swelling were determined for all resins in order to relate the adsorption performances to the resin properties. The results are summarized in Table 3. The BET surface area of M500 is not determined since this is a gel type resin.

The particle size diameter determined is the diameter of the wet resins and is determined by the swelling of the material (explained later) and by the manufacturing method. ${ }^{29}$ The particle size decreases in the following order: $\mathrm{M} 500\left(\mathrm{OH}^{-}\right), \mathrm{MP} 62, \mathrm{XAD} 4$, $\mathrm{M} 500\left(\mathrm{Cl}^{-}\right)$, Optipore and PVP. The difference in particle size between $\mathrm{M} 500\left(\mathrm{OH}^{-}\right)$and $\mathrm{M} 500\left(\mathrm{Cl}^{-}\right)$is explained by differences in swelling as explained below. The particle size is important for adsorption kinetics, but does not influence the adsorption capacity. It is therefore not further considered.

The BET surface area decreases in the following order: Optipore, XAD4, PVP and MP62. The BET surface area is high for the polymeric adsorbers Optipore and XAD4 and low for the ion 
Table 3. Resin properties

\begin{tabular}{|c|c|c|c|c|c|c|}
\hline Resin & $\begin{array}{c}\text { Particle } \\
\text { size diameter }[\mu \mathrm{m}]\end{array}$ & $\begin{array}{c}\text { BET surface } \\
\text { area }\left[\mathrm{m}^{2} \mathrm{~g}^{-1}{ }_{\text {resin }}\right]\end{array}$ & $\begin{array}{c}\text { Mean pore } \\
\text { size }[\mathrm{nm}]\end{array}$ & $\begin{array}{l}\text { Pore volume } \\
{\left[\mathrm{mL} \mathrm{g}^{-1} \text { resin }\right]} \\
\text { at } \mathrm{p} / \mathrm{p}_{0}=0.99\end{array}$ & $\begin{array}{c}\text { Wateruptake } \\
{\left[\mathrm{mL}_{\left.\mathrm{H} 2 \mathrm{O} \mathrm{g}^{-1} \text { dry resin }\right]}\right.}\end{array}$ & $\begin{array}{c}\text { Swelling } \\
{\left[\mathrm{mL}_{\mathrm{H} 20} \mathrm{~g}^{-1} \text { dry resin }\right]}\end{array}$ \\
\hline XAD4 & 590 & $746.4 \pm 1.5$ & 6 & 1.11 & 2.4 & 0.1 \\
\hline Optipore & 557 & $1321.2 \pm 1.5$ & 56 & 0.85 & 2.8 & 1.1 \\
\hline MP62 & 625 & $39.3 \pm 0.2$ & 40 & 0.12 & 2.1 & 0.6 \\
\hline PVP & 366 & $53.7 \pm 0.1$ & 30 & 0.14 & 2.4 & 0.8 \\
\hline $\mathrm{M} 500\left(\mathrm{OH}^{-}\right)$ & 660 & - & - & - & 2.6 & 2.3 \\
\hline M500 ( $\left.\mathrm{Cl}^{-}\right)$ & 585 & - & - & - & 0.9 & 1.3 \\
\hline
\end{tabular}

exchange resins PVP and MP62. The surface areas of Optipore and XAD are comparable with the areas given by the manufacturers $\left(>1100 \mathrm{~m}^{2} \mathrm{~g}^{-1}\right.$ and $750 \mathrm{~m}^{2} \mathrm{~g}^{-1}$, respectively $\left.{ }^{21,22}\right)$. Surface areas of MP62 and PVP are not provided by the manufacturer. Because ion exchange resins are manufactured to contain many accessible ion exchange groups while the structure is $\mathrm{pH}$ resistant and capable of resisting $\mathrm{pH}$ induced swelling and shrinkage, surface area is of minor importance compared with mechanical strength, and ion exchange resins therefore have smaller surface areas. It is expected that when the chemical composition is similar, a larger surface area will lead to a higher adsorption capacity for the solute than when compared to a similar resin with a lower surface area. As such we expect Optipore to show a higher adsorption capacity for HMF than XAD4. The macroporous ion exchange resins MP62 and PVP show much lower BET surface areas and although they contain polar groups that could enhance HMF adsorption they are expected to show lower adsorption capacities.

The pore sizes of all resins are comparable except for XAD4, which has a smaller pore size. The pore sizes are determined by the production method. ${ }^{29}$ Pore sizes larger than $\sim 5 \mathrm{~nm}$ are suitable for the adsorption of small solutes because the solutes can migrate through the pores to occupy the entire surface area. ${ }^{30}$ Since HMF is a small solute $\left(126.11 \mathrm{~g} \mathrm{~mol}^{-1}\right)$, all of these resins are suitable for HMF adsorption.

Pore volume from low to high is in the following order: MP62, PVP, Optipore and XAD4. M500 is a gel type resin and therefore contains no pores. Gel type resins possess higher loading capacities but have diffusion limitations in their adsorption kinetics. Macroporous resins show lower adsorption capacity but the adsorption sites are more readily available.

Water uptake of the resins shows, except for $\mathrm{M} 500\left(\mathrm{Cl}^{-}\right)$, only little variation and is from low to high in the following order: MP62, PVP and XAD4, M500( $\left.\mathrm{OH}^{-}\right)$, Optipore. $\mathrm{M} 500\left(\mathrm{Cl}^{-}\right)$has a lower water uptake due to lower swelling of the matrix.

Swelling of the resins is from low to high in the following order: XAD4, MP62, PVP, Optipore, M500(Cl-) and M500 $\left(\mathrm{OH}^{-}\right)$. Swelling of the resins is determined by the nature of the matrix, the degree of crosslinking, the macrostructure, the nature of the functional groups, the ion exchange capacity, and the nature of the counter ion. ${ }^{31}$ Swelling of the resins can affect the adsorption capacity in different manners. A higher degree of swelling could influence the adsorption by making the adsorption sites better available. ${ }^{29}$ Furthermore swelling increases the polymer volume thereby increasing the absorption area of the polymer matrix. ${ }^{29}$ The water in the resins can be located in the pores, in the matrix of the resins or in a combination of both. In the first case no swelling is observed while in the second case swelling of the matrix is observed.
Although the water uptake of XAD4 is high, the swelling is very low. This indicates that the water present in the resin is mostly located in the pores of the resin. XAD4 consists of styrene-DVB and the apolar structure of the matrix explains the low swelling in water. It is generally accepted that water absorption in styrene-DVB polymers is due to filling of the pores and not by swelling of the matrix, ${ }^{32,33}$ although swelling in water has been observed when the polymerization occurred in a good solvent for the matrix. ${ }^{32}$

The observed higher swelling of PVP and MP62 compared with XAD4 was expected since their matrix is less polar due to the introduction of the polar alkaline groups. ${ }^{31}$

The relatively high swelling of Optipore is unexpected since, like XAD4, Optipore is specified as a apolar resin. ${ }^{22}$ This is probably explained by the polymerization method. According to Xu et al., ${ }^{29}$ Optipore is a hypercrosslinked polymer. These types of adsorbents are, after preparation in emulsion polymerization, further crosslinked with a crosslinker while swollen in a good solvent. The crosslinkers used for hypercrosslinking usually contain oxygen or chlorine containing reactive groups. ${ }^{29}$ If the crosslinking reaction is incomplete, these groups are still present in the polymer matrix, thereby increasing the hydrophilicity of the polymer. Verne at $a l^{8}$ also mention that Optipore contains hydrophilic groups. Furthermore Yan et al. ${ }^{32}$ observed that these hypercrosslinked resins, in contrast to the conventional macroporous resins, do swell in water at high degrees of crosslinking. This is caused by the inner strain caused by the high degree of crosslinking, which is released by swelling of the polymer. Although XAD4 and Optipore were chosen as resins with comparable chemical structure, these results show that this might not be the case. Not only the difference in surface area, but also the difference in degree of swelling, as well as the possibility of the presence of polar groups could affect the respective adsorption capacities.

M500 shows very high swelling due to the gel type structure (e.g. crosslinking) of the resin. The resin swells a lot more when $\mathrm{OH}^{-}$is chosen as counterion than when $\mathrm{Cl}^{-}$serves as counterion of the ammonium group, as the first counterion is known to cause the largest swelling of the resin. ${ }^{31}$ Since $\mathrm{M} 500\left(\mathrm{OH}^{-}\right)$shows much more swelling than $\mathrm{M} 500\left(\mathrm{Cl}^{-}\right)$it is therefore expected that the $\mathrm{HMF}$ adsorption capacity of $\mathrm{M} 500\left(\mathrm{OH}^{-}\right)$is higher than that of $\mathrm{M} 500\left(\mathrm{Cl}^{-}\right)$.

We realize that the water mass balance does not add up. The water uptake $\left[\mathrm{mL} \mathrm{g}^{-1}\right.$ dry resin] is larger than the sum of the pore volume $\left[\mathrm{mL} \mathrm{g}^{-1}\right.$ dry resin $]$ and the swelling $\left[\mathrm{mL} \mathrm{g}^{-1}\right.$ dry resin]. This is likely due to the use of a combination of different techniques (e.g. nitrogen adsorption or water adsorption) and errors in the measurement. Nitrogen is a smaller molecule and can access smaller pores, at the same time swelling due to water affects pore volume and pore accessibility of some resins. Although the numbers do not fully match, the water uptake and swelling give a 


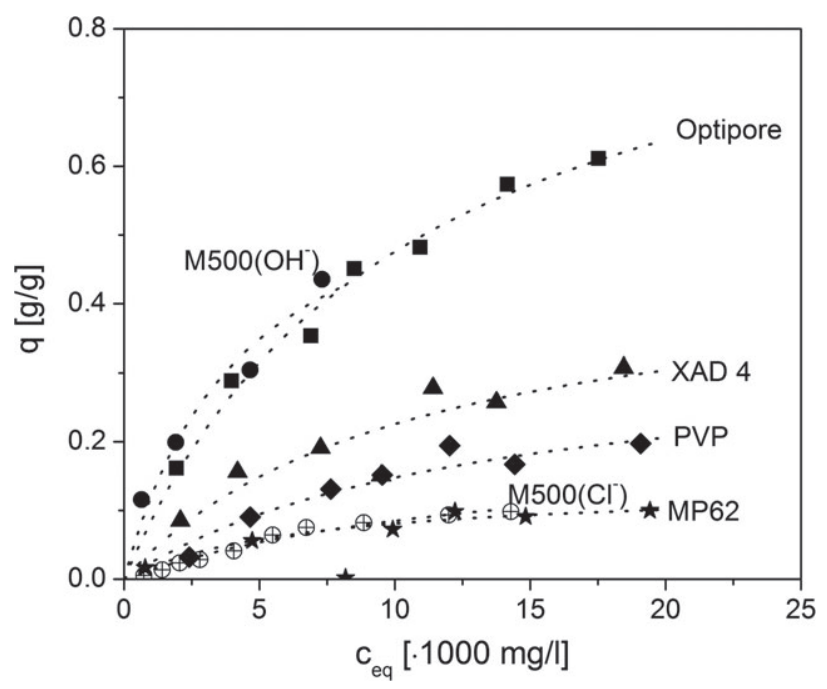

Figure 1. $\mathrm{HMF}$ adsorption isotherms $\left(\left[\mathrm{C}_{0, \mathrm{HMF}}\right]=1000-20000 \mathrm{mg} \mathrm{L}^{-1}\right)$. The dotted lines show the fit according to the Langmuir isotherms, obtained Langmuir parameters are summarized in Table 4.

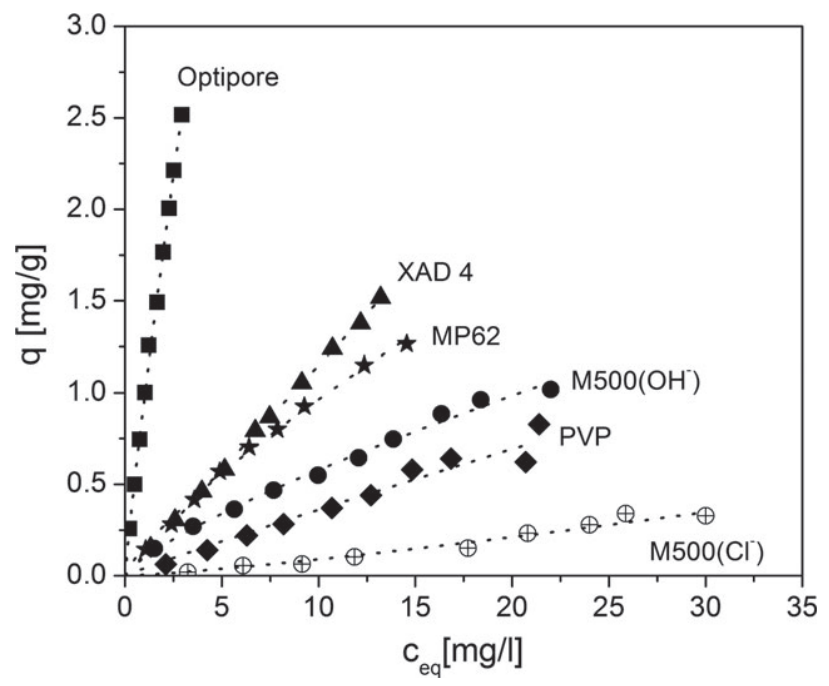

Figure 2. HMF adsorption isotherms $\left(\left[\mathrm{c}_{0}, \mathrm{HMF}\right]=1-30 \mathrm{mg} \mathrm{L}^{-1}\right)$. The dotted lines show the fit according to Freundlich (the obtained Freundlich parameters are summarized in Table 4).

good idea of the mechanisms of water uptake (in the pore volume, due to swelling of the matrix or a combination of both).

\section{Adsorption isotherms}

HMF adsorption

HMF adsorption isotherms were determined to obtain information on the affinity and capacity of the different resins for HMF. The HMF adsorption isotherms are shown in Fig. 1 for high HMF concentrations (1000-20 000 $\mathrm{mg} \mathrm{L}^{-1}$ ) and Fig. 2 for low HMF concentrations $\left(1-30 \mathrm{mg} \mathrm{L}^{-1}\right)$. The data are fitted with Langmuir (1000-20 $\left.000 \mathrm{mg} \mathrm{L}^{-1}\right)$ and Freundlich adsorption isotherms $\left(1-30 \mathrm{mg} \mathrm{L}^{-1}\right)$. The fitted curves are shown in the figures as well and the adsorption isotherm parameters are given in Table 4.

Figure 1 shows the adsorption isotherms for all resins of HMF at high concentrations. All resins show a type 1 Langmuir adsorption. Type 1 adsorption is limited to a single monolayer of adsorbate on the adsorbent surface characterized by saturation at high concentrations. Type 1 adsorption is often seen when the solvent has low affinity for the surface and does not compete for adsorption with the solute. ${ }^{34}$ Type 1 Langmuir adsorption is also confirmed by the modeled data, since $\mathrm{R}^{2}$ is larger than 0.95 for all resins except for XAD4, which shows a lower $\mathrm{R}^{2}$ (see Table 4). Although XAD4 shows a lower $R^{2}$ due to more scatter in the data, the shape of the measured data still justifies the assumption of type 1 Langmuir adsorption. Langmuir type adsorption of furans on styrene-DVB resins with and without anion exchange groups was also observed by several others. $5,14,35$

The adsorption capacity of the resins increases in the following order: MP62, M500( $\left.\mathrm{Cl}^{-}\right), \mathrm{PVP}, \mathrm{XAD4}, \mathrm{M} 500\left(\mathrm{OH}^{-}\right)$and Optipore. The adsorption isotherms of MP62 and $M 500\left(\mathrm{Cl}^{-}\right)$show the lowest adsorption capacity and are saturated at the measured concentrations. MP62 has a low surface area and therefore less available adsorption sites. $\mathrm{M} 500\left(\mathrm{Cl}^{-}\right)$swells only little and adsorption sites cannot be reached by diffusion through the gel. Since no other groups than aromatic rings are present in the matrices of XAD4 and Optipore, adsorption of HMF on Optipore and XAD is established by $\pi-\pi$ interactions between the styrene matrix and the ring of HMF. Adsorption of the polar groups of HMF on the apolar matrix of XAD or Optipore of HMF is unlikely. XAD4 shows a lower adsorption capacity than Optipore. This is related to the surface area of the resins. The surface area of Optipore is 1321.2 $\mathrm{m}^{2} \mathrm{~g}^{-1}$ while the surface area of XAD4 is $746.4 \mathrm{~m}^{2} \mathrm{~g}^{-1}$ only. The ratio of maximum adsorption capacity to BET surface area is $0.63 \mathrm{mg}_{\mathrm{HMF}}$ $\mathrm{m}^{-2}$ and $0.73 \mathrm{mg}_{\text {HMF }} \mathrm{m}^{-2}$ for XAD4 and Optipore, respectively. Since the swelling experiments showed that Optipore swells while XAD4 does not, we believe that this causes the relatively higher HMF adsorption since swelling increases the accessibility of the adsorption sites. ${ }^{29}$

The adsorption capacities of the macroporous anion exchange resins MP62 and PVP is much lower than that of Optipore and XAD4. This is explained by the small surface area of these resins.

$\mathrm{M} 500\left(\mathrm{OH}^{-}\right)$shows a very high adsorption capacity while $\mathrm{M} 500\left(\mathrm{Cl}^{-}\right)$shows a very low adsorption capacity. This is caused by the swelling of the resin, which depends on the counter ion. M500 $\left(\mathrm{Cl}^{-}\right)$swells only little while $\mathrm{M} 500\left(\mathrm{OH}^{-}\right)$has a huge degree of swelling. This is directly reflected in a lower adsorption capacity.

The affinity of the resins could provide more insight to the HMF adsorption mechanism of the resins. It is clear that HMF adsorbs on XAD4 and Optipore by $\pi-\pi$ bonds since no other interactions are available. For the other resins an increased or reduced affinity compared with XAD4 and Optipore is observed, depending on the affinity of the resin for HMF. The affinity of the resins is indicated by the affinity parameter $b$ of the Langmuir isotherm and is determined by the slope of the curve at lower equilibrium concentration ranges when the curve is still linear. Values of $b$ were obtained by fitting the data of Fig. 1 to the Langmuir equation (see Table 4). The values obtained for $b$ are comparable for all resins. Since there are not so many data points in the linear part of the graph that determine $b$, the value of $b$ is further investigated by analyzing the adsorption isotherms at low concentrations (Fig. 2).

Figure 2 shows the adsorption isotherms of the resin at low concentrations. The adsorption capacity of the resins for HMF increases in the following order: $\mathrm{M} 500\left(\mathrm{Cl}^{-}\right), \mathrm{PVP}, \mathrm{M} 500\left(\mathrm{OH}^{-}\right), \mathrm{MP} 62$, XAD4 and Optipore. $1 / n$ and $K$ are obtained by modeling the data to the Freundlich isotherm (Equation (4) and Table 4). Although the data fitted with Freundlich describe the adsorption isotherms well, $1 / n$ and $K$ have no physical meaning in this case, as the isotherms are mostly linear and consequently $1 / n$ and $K$ are correlated. 
Table 4. Adsorption isotherm parameters obtained from the data in Figs 1,2 and 3

\begin{tabular}{|c|c|c|c|c|c|c|c|c|}
\hline & \multicolumn{3}{|c|}{ Langmuir } & \multicolumn{3}{|c|}{ Freundlich } & \multicolumn{2}{|l|}{ Henry } \\
\hline & $b\left[\mathrm{~L} \mathrm{~g}^{-1} \mathrm{HMF}\right]$ & $q_{\max }\left[g_{\text {HMF }} \mathrm{g}^{-1}{ }_{\text {resin }}\right]$ & $\mathrm{R}^{2}$ & $K\left[\mathrm{Lg}^{-1}{ }_{\text {resin }}\right]$ & $1 / n$ & $\mathrm{R}^{2}$ & $b\left[\mathrm{~L} \mathrm{mg}^{-1} \mathrm{HMF}\right]$ & $\mathrm{R}^{2}$ \\
\hline XAD 4 & 0.09 & 0.47 & 0.82 & 0.12 & 0.98 & 1.00 & 0.24 & 0.99 \\
\hline Optipore & 0.10 & 0.97 & 0.98 & 0.97 & 0.89 & 1.00 & 0.86 & 0.99 \\
\hline MP 62 & 0.15 & 0.14 & 0.97 & 0.16 & 0.78 & 1.00 & 0.60 & 0.98 \\
\hline PVP & 0.08 & 0.34 & 0.92 & 0.04 & 0.94 & 0.95 & 0.11 & 0.96 \\
\hline $\mathrm{M} 500\left(\mathrm{OH}^{-}\right)$ & 0.22 & 0.66 & 0.95 & 0.10 & 0.77 & 0.99 & 0.07 & 0.99 \\
\hline $\mathrm{M} 500\left(\mathrm{Cl}^{-}\right)$ & 0.07 & 0.20 & 0.98 & 0.01 & 1.23 & 0.95 & 0.05 & 0.95 \\
\hline
\end{tabular}

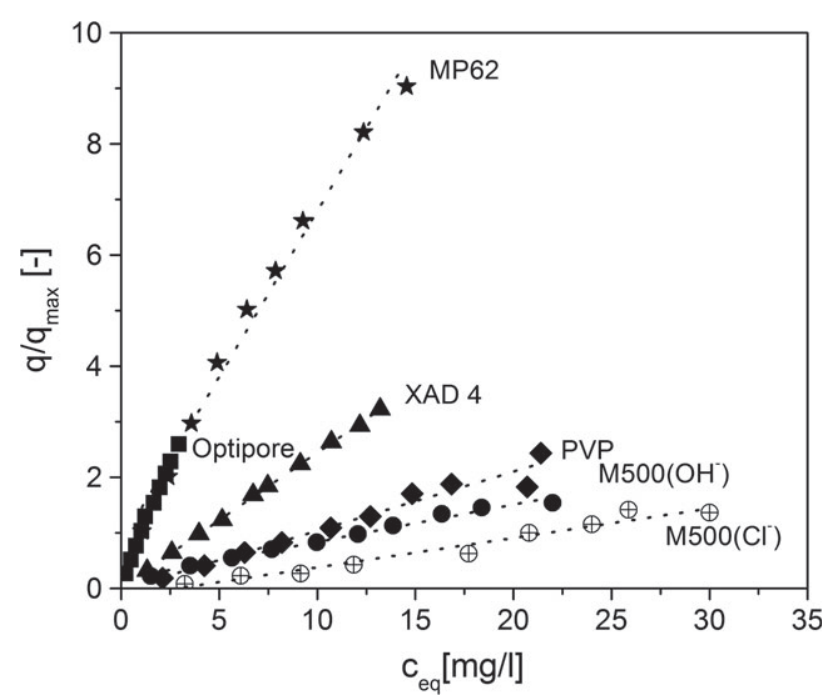

Figure 3. $\mathrm{HMF}$ adsorption isotherms $\left(\left[\mathrm{c}_{0}, \mathrm{HMF}\right]=1-30 \mathrm{mg} \mathrm{L}^{-1}\right)$. The dotted lines show the fit based on Henry (the obtained Henry parameters are summarized in Table 4).

However, when the maximum capacity $\left(q_{\max }\right)$ obtained from the adsorption isotherms at high concentrations (Fig. 1, Table 4) is used, more information on the affinity at low concentrations can be obtained. For low concentrations ( $b^{*} c_{e q}<<1$ ) Equation (3) can be simplified to Henry's law:

$$
\frac{q}{q_{\max }}=b \cdot c_{e q}
$$

The adsorption capacity ( $q$ ) measured at low concentrations (Fig. 2) is divided by the maximum adsorption capacity $\left(q_{\max }\right)$ obtained at high concentrations (Table 4). Figure 2 was recalculated using the maximum adsorption capacity and Fig. 3 was obtained. Equation (5) shows that the slope of the adsorption isotherms is equal to the affinity parameter $b$.

The data fits Henry's law well since $\mathrm{R}^{2}>0.95$ (Table 4). The slope and therefore the affinity is highest for Optipore, immediately followed by MP62 and subsequently XAD4, PVP, M500 $\left(\mathrm{OH}^{-}\right)$and $\mathrm{M} 500\left(\mathrm{Cl}^{-}\right)$. Since the adsorption isotherm is corrected for the maximum capacity, the resin swelling and surface area have no effect on the slope of the graph. Optipore mainly consists of a styrene-DVB matrix and since the affinity of HMF is largest for this resin, it shows that $\pi-\pi$ stacking is the main contributor to HMF adsorption. XAD4 contains the same chemical composition as Optipore but shows a lower affinity for HMF. This is caused by the altered morphology of the hypercrosslinked Optipore compared with that of XAD4 as was shown before by Jerabek et al..$^{35}$ for comparable resins, who showed that the micropores formed by hypercrosslinking enhance the adsorbence at low concentration similar to adsorption in micropores in gas-solid adsorption.

It appears that the addition of a tertiary amine enhances the affinity of HMF for the resin since the affinity of MP62 is higher than that of XAD4 and almost comparable with Optipore. It is possible that the polar groups of HMF form hydrogen bonds with the tertiary amine of MP62, as was suggested by Fargues et al. ${ }^{14}$ as a mechanism for furfural adsorption on tertiary amines. The adsorption mechanism of HMF on MP62 is further discussed when glucose adsorption and competitive adsorption is evaluated.

Addition of a pyridine to the matrix reduces the affinity of the resins for HMF, as the affinity of PVP is lower than that of XAD4 and Optipore. We expected the bulky aromatic group to show $\pi-\pi$ stacking with HMF and hydrogen bond formation between the polar groups of HMF with the amine of the pyridine, thereby enhancing the affinity. However, the affinity is reduced compared with XAD4 and Optipore upon addition of a pyridine group. We hypothesize that since the aromatic group does not seem to contribute to HMF adsorption, it blocks the access to the styrene matrix thereby reducing HMF adsorption, this was also a considered mechanism for other ion exchange resins by Fargues et al. ${ }^{14}$

Addition of strong ion exchange groups such as in $\mathrm{M} 500\left(\mathrm{OH}^{-}\right.$ and $\mathrm{Cl}^{-}$) also does not enhance the affinity of the materials for $\mathrm{HMF}$ as these resins show very low affinity constants. The slope of $\mathrm{M} 500\left(\mathrm{OH}^{-}\right)$is slightly higher than that of $\mathrm{M} 500\left(\mathrm{Cl}^{-}\right)$but we believe that is caused by the value of $q_{\max }$, which is very different for both resins and susceptible to a certain error. The affinities of the resins are therefore comparable and differences in adsorption capacity are likely caused by different swelling due to the different counter ions. The reduced affinity of M500 compared with the other styrene-DVB resins might also be caused by steric hindrance of the styrene matrix by the quaternary amine.

The results on the HMF adsorption capacity (low and high concentration) show that the main factor influencing HMF adsorption capacity of the styrene-DVB resins is the surface area. The main mechanism for HMF adsorption for all resins is $\pi-\pi$ stacking with the styrene-DVB matrix. It appears that the addition of polar anion exchange groups reduces the affinity, probably caused by steric hindrance. In the case of the tertiary amine, the adsorption mechanism is less obvious. It is possible that HMF adsorption is caused by $\pi-\pi$ stacking or hydrogen bonding or a combination of both.

\section{Glucose adsorption}

In the targeted industrial application glucose is abundantly present while HMF is present only in trace amounts. As such, 


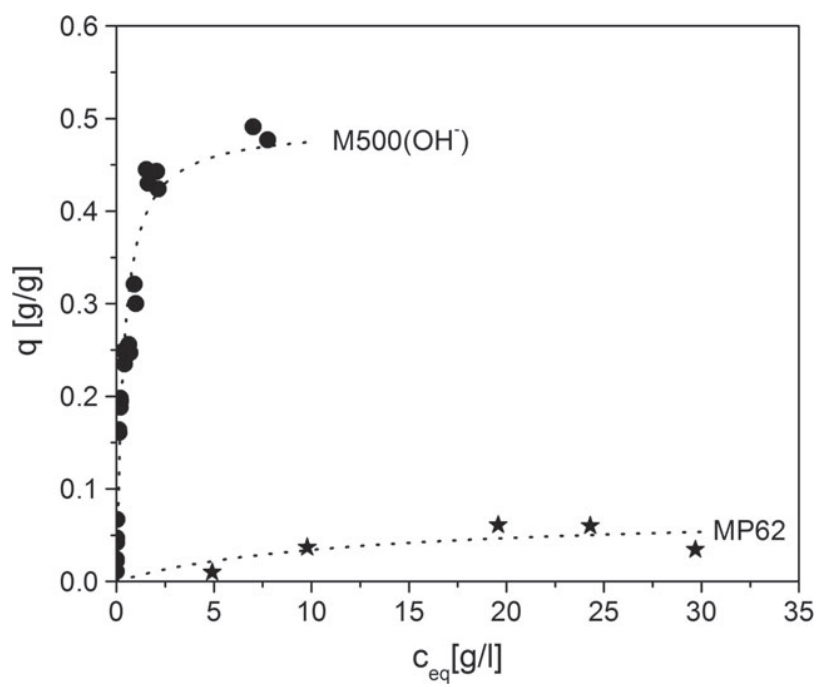

Figure 4. Glucose adsorption isotherms of $\mathrm{M} 500\left(\mathrm{OH}^{-}\right)$and $\mathrm{MP62}$ $\left(\left[c_{0}\right.\right.$, glucose $\left.]=1-30 \mathrm{~g} \mathrm{~L}^{-1}\right)$.

undesired glucose adsorption may affect HMF adsorption by competitive adsorption if both components exhibit similar adsorption mechanisms. Additionally sugar loss due to adsorption of sugars (e.g. glucose) reduces the final fermentation yield. Glucose adsorption for all resins was therefore studied as well. The glucose adsorption isotherms of $\mathrm{M} 500\left(\mathrm{OH}^{-}\right)$and MP62 are given in Fig. 4. Glucose adsorption was not observed for XAD4, PVP, $\mathrm{M} 500\left(\mathrm{Cl}^{-}\right)$and Optipore.

Figure 4 shows that the weak and strong ion exchange resins MP62 and M500 $\left(\mathrm{OH}^{-}\right)$show glucose adsorption. Since glucose adsorption was not observed for XAD4 and Optipore, adsorption does not occur at the styrene-DVB matrix of the resins. This is in agreement with Weil et al. ${ }^{5}$ The absence of glucose adsorption on PVP is in line with the work of Xie et al. ${ }^{10}$ However, these studies were both performed with column experiments. The observed glucose adsorption on MP62 is most probably due to hydrogen bonding of the alcohol group of glucose to the tertiary amine. Saari et al. ${ }^{36}$ also observed glucose adsorption on a weak anion exchanger. The amount of glucose adsorption at these concentrations was comparable but the curve did not reach maximum adsorption and was linear instead of following Langmuir. This could be related to the unknown differences in physical properties (e.g. pore size, surface area) of the resins used in this work and in the work of Saari et al. Although we believe that glucose binds to MP62 through hydrogen bonding we do not observe glucose adsorption on PVP.

Although glucose is known not to adsorb on strong ion exchange resins, ${ }^{37}$ examples of glucose adsorption on strong ion exchange resin in their $\mathrm{OH}^{-}$form were found. ${ }^{15,38}$ The mechanism of this glucose adsorption on a quaternary ammonium countered with $\mathrm{OH}^{-}\left(\mathrm{M} 500\left(\mathrm{OH}^{-}\right)\right)$is, however, unclear since hydrogen bonding with a quaternary ammonium is not possible. ${ }^{39}$ According to Nilvebrant et al. ${ }^{15}$ glucose adsorption is caused by the tendency of glucose to ionize and form ionic bonds with quaternary ammonium. We believe that since glucose has a very high dissociation factor $\left(p K a>14^{20}\right)$ and therefore only dissociates at high $\mathrm{pH}$, this mechanism might be an explanation for glucose adsorption at high $\mathrm{pH}$, but it does not explain the adsorption of glucose at neutral $\mathrm{pH}$, as was measured in this research and at $\mathrm{pH} 5.5$ by Nilvebrant et al. ${ }^{15}$ Since glucose adsorption is

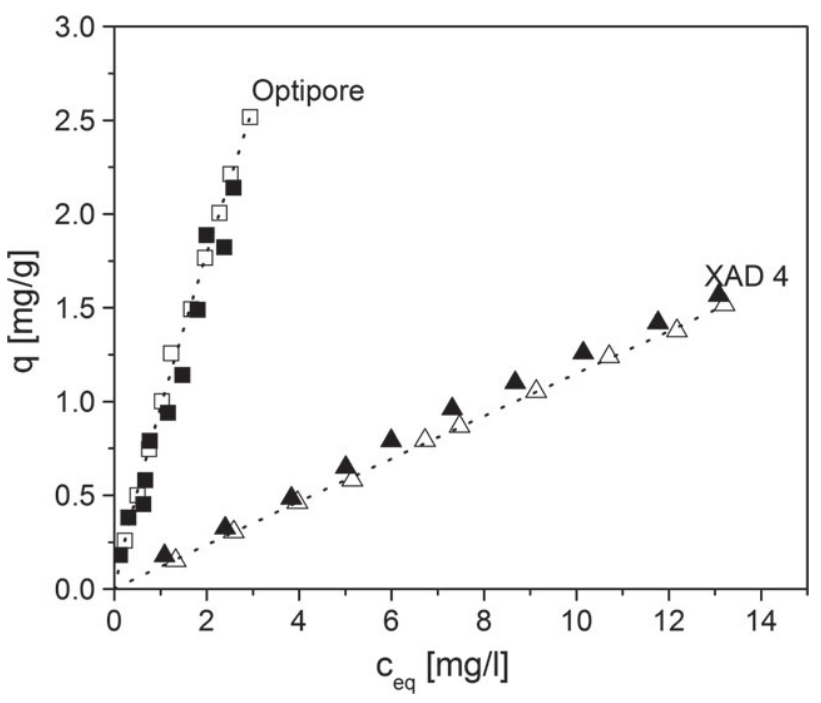

Figure 5. HMF adsorption in water (open symbols) and the presence of glucose $\left(\left[c_{\text {glucose }}\right]=100 \mathrm{~g} \mathrm{~L}^{-1}\right)$ (closed symbols) for Optipore and XAD $4\left(\left[c_{0}\right.\right.$, $\left.\mathrm{HMF}]=1-30 \mathrm{mg} \mathrm{L}^{-1}\right)$.

not observed for the $\mathrm{Cl}^{-}$form (this research) or the $\mathrm{SO}_{4}{ }^{2-}$ form (Nilvebrandt et al. ${ }^{15}$ ) of the ammonium salt, hydrogen bonding with the counter ion $\mathrm{OH}^{-}$can be an explanation for glucose adsorption on $\mathrm{M} 500\left(\mathrm{OH}^{-}\right)$.

The very high glucose adsorption on $\mathrm{M} 500\left(\mathrm{OH}^{-}\right)$compared with MP62 is due to the different matrix structure (e.g. gel type vs macroporous). A higher degree of crosslinking tightens structure of the matrix, making this less accessible for the large hydrate glucose molecule as was also shown for cation exchange resins. ${ }^{40-43}$

\section{Competitive adsorption}

The effect of the presence of glucose on HMF adsorption was studied as well to examine if glucose and HMF compete for adsorption sites. As described, the main mechanism for HMF adsorption of all resins is $\pi-\pi$ stacking, however, hydrogen bonding may play a role for the resin MP62. To verify the importance of competitive adsorption of HMF and glucose Fig. 5 shows the HMF adsorption isotherms in the presence of glucose determined for XAD4 and Optipore. It was not possible to determine the HMF adsorption on MP62, PVP and M500 at low HMF concentrations as contamination of the resins related to the production of the resins hindered HMF analysis for the ion exchange resins at low concentration. Although the anion exchange resins were very intensively rinsed with water until contaminants were no longer visible with UV-VIS before the adsorption experiments, when the resins were exposed to the glucose solution in the adsorption experiment, they released additional contaminants. This, combined with the presence of glucose, hindered accurate HMF analysis at this concentration range. However, in case competitive adsorption occurs, this would also be visible at high concentrations. Therefore HMF adsorption for $\mathrm{M} 500\left(\mathrm{OH}^{-}\right), \mathrm{PVP}$ and MP62 in the presence of glucose was determined at higher HMF concentrations $\left(0-20000 \mathrm{mg} \mathrm{L}^{-1}\right)$ in order to be still able to evaluate the contribution of competitive adsorption between HMF and glucose.

Figure 5 clearly shows that for the two resins without specific functional groups, competitive adsorption is essentially not observed. In the presence of glucose or not, the same amount of HMF is adsorbed over the full HMF concentration range 


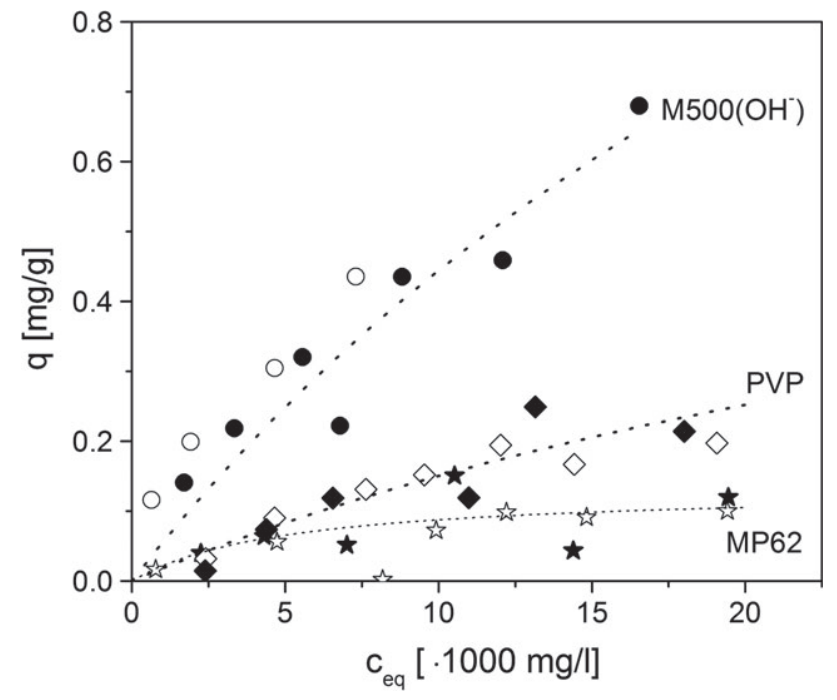

Figure 6. HMF adsorption in water (open symbols) and the presence of glucose $\left(\left[c_{\text {glucose }}\right]=100 \mathrm{~g} \mathrm{~L}^{-1}\right)$ (closed symbols) for M500, PVP, MP62 ([c $c_{0}$, HMF $]=1000-20000 \mathrm{mg} \mathrm{L}^{-1}$ ).

investigated. The resins $\mathrm{M} 500\left(\mathrm{OH}^{-}\right), \mathrm{PVP}$ and MP62 show similar behavior (Figure 6), however, the adsorption isotherms show more scatter. As discussed earlier, this is caused by contaminants, related to the production of the resins and released from the anion exchange resins.

The absence of competitive adsorption on M500 and MP62 shows that the adsorption mechanism for HMF differs from that of glucose, which confirms that HMF adsorption is established through $\pi-\pi$ interactions. We believe that glucose adsorption on MP62 is established through hydrogen bonding with the tertiary amine. Although HMF has an alcohol and a keton group that could bind through hydrogen bonds to MP62 as well, the absence of competitive adsorption shows that this mechanism does not play a role in HMF adsorption on MP62. This result also confirms that HMF adsorption for all resins is predominantly through $\pi-\pi$ bonding with the styrene matrix.

Fargues et al. ${ }^{14}$ suggest that furfural adsorption on a strong anion exchange resin with a styrene matrix is due to hydrogen bonding of the polar keton group of furfural to the quaternary amine. We believe however that the only possibility for hydrogen bonding is with the $\mathrm{OH}^{-}$counter ion of the quaternary ammonium. We believe that glucose binds to $\mathrm{M} 500\left(\mathrm{OH}^{-}\right)$through hydrogen bonding and since competitive adsorption between glucose and HMF is not observed, hydrogen bonding does not play a role in HMF adsorption.

All competitive adsorption isotherm graphs show that the presence of glucose does not affect the HMF adsorption capacity of the resins. Additionally, this also shows that the presence of glucose does not alter the solubility of HMF, since the HMF adsorption capacity of the resins is not affected by the presence of glucose.

\section{Temperature effect}

The HMF adsorption isotherms show that styrene-DVB based resins are good adsorbers for HMF. The affinity of these adsorbers for HMF is high, however this could make subsequent desorption difficult. Regeneration with steam is a common method to desorb solutes from a column. ${ }^{44}$ Furthermore the pretreatment methods to extract sugars from lignocellulosic mass often include a temperature increase (e.g. liquid hot water extraction,

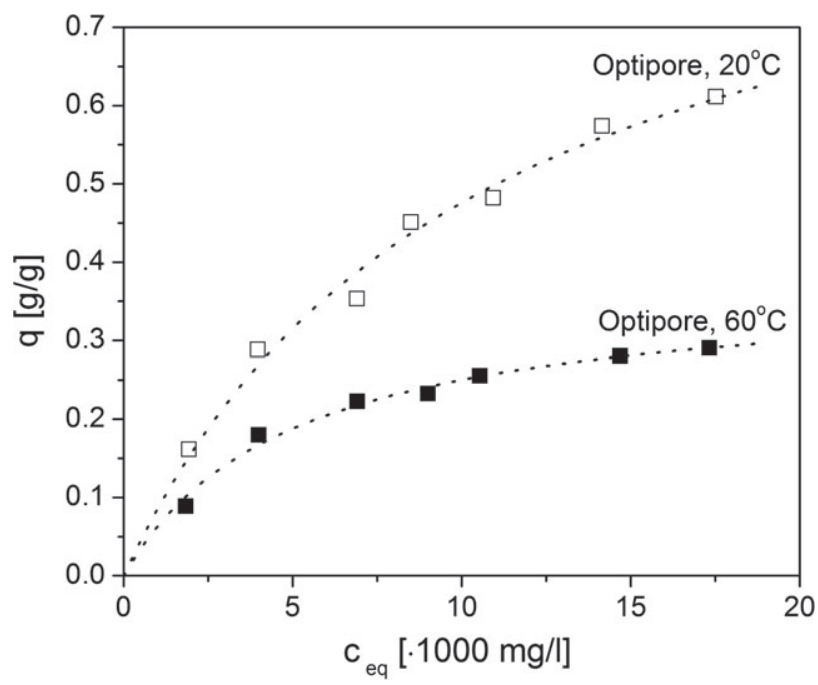

Figure 7. $\mathrm{HMF}$ adsorption on Optipore at $20^{\circ} \mathrm{C}$ and $60^{\circ} \mathrm{C}\left(\left[\mathrm{c}_{0}\right.\right.$, $\mathrm{HMF}]=1000-20000 \mathrm{mg} \mathrm{L}^{-1}$ ).

steam explosion) that affects the adsorption thermodynamics. So additionally we investigated the effect of temperature on $\mathrm{HMF}$ adsorption for Optipore at $20^{\circ} \mathrm{C}$ and at $60^{\circ} \mathrm{C}$ (Fig. 7).

Figure 7 clearly shows that the adsorption capacity of Optipore for HMF is higher at lower temperatures. This confirms that adsorption is established by physical adsorption. This effect was also observed for XAD4 by Weil et al. ${ }^{5}$ The efficiency of the adsorbers at higher temperatures is reduced, but this reduced affinity can also be used to regenerate the column after saturation by increasing the temperature. This is especially effective at higher HMF concentrations.

\section{CONCLUSIONS}

Furan derivatives can be removed from water and sugar solutions with styrene based (ion exchange) polymeric resins. For efficient removal, a high surface area of the resin is a key property. Although introduction of polar groups in the form of tertiary amines appears to increase the affinity of the resin material for HMF, these groups also introduce affinity for glucose resulting in loss of fermentable sugar. However the presence of glucose did not affect the HMF adsorption capacity and solubility and competition between HMF and glucose for adsorption sites was not observed in the ion exchange resins. HMF adsorption is likely established by $\pi-\pi$ interactions between the styrene matrix and the ring of the furan, while glucose adsorption is predominantly by hydrogen interactions with the polar groups of the ion exchange groups. Optipore shows a high specificity for HMF adsorption while it does not exhibit specificity for glucose. This makes it an excellent adsorber for HMF removal from hydrolysate for the fermentation of glucose.

\section{ACKNOWLEDGEMENTS}

This work was carried out within project SC-00-04 of the Institute for Sustainable Process Technology (ISPT), The Netherlands.

\section{REFERENCES}

1 Ranjan R, Thust S, Gounaris CE, Woo M, Floudas CA, Keitz Mv, et al., Adsorption of fermentation inhibitors from lignocellulosic biomass 
hydrolyzates for improved ethanol yield and value-added product recovery. Micropor Mesopor Mater 122:143-148 (2009).

2 de Mancilha IM and Karim MN, Evaluation of ion exchange resins for removal of inhibitory compounds from corn stover hydrolyzate for xylitol fermentation. Biotechnol Progress 19:1837-1841 (2003).

3 Mills TY, Sandoval NR and Gill RT, Cellulosic hydrolysate toxicity and tolerance mechanisms in Escherichia coli. Biotechnol Biofuels 2:1 -11 (2009).

4 Huang HJ, Ramaswamy S, Tschirner UW and Ramarao BV, A review of separation technologies in current and future biorefineries. Sep Purif Technol 62:1-21 (2008).

5 Weil JR, Dien B, Bothast R, Hendrickson R, Mosier NS and Ladisch MR, Removal of fermentation inhibitors formed during pretreatment of biomass by polymeric adsorbents. Indust Eng Chem Res 41:6132-6138 (2002).

6 Nanoti A, Gupta P, Dasgupta S, Garg MO and Goswami AN, Process studies for development of adsorption technology for furfural recovery from waste water. Environ Progress 27:308-312 (2008).

7 Gupta P, Nanoti A, Garg MO and Goswami AN, The removal of furfural from water by adsorption with polymeric resins. Sep Sci Technol 36:2835-2844 (2001).

8 Vern C, Gabbert C, Schueller J, Galt S, C. J, K. M, et al., The beet sugar factory of the future. Int Sugar J 97:310-316 (1995).

9 de Carvalho W, Canilha L, Mussatto SI, Dragone G, Morales MLV and Solenzal AIN, Detoxification of sugarcane bagasse hemicellulosic hydrolysate with ion-exchange resins for xylitol production by calcium alginate-entrapped cells. J Chem Technol Biotechnol 79:863-868 (2004).

10 Xie Y, Phelps D, Lee C-H, Sedlak M, Ho N and Wang NHL, Comparison of two adsorbents for sugar recovery from biomass hydrolyzate. Ind Eng Chem Res 44:6816-6823 (2005).

11 Canilha L, de Almeida e Silva JB and Solenzal AIN, Eucalyptus hydrolysate detoxification with activated charcoal adsorption or ion-exchange resins for xylitol production. Process Biochem 39:1909-1912 (2004).

12 Singh S, Srivastava VC and Mall ID, Fixed-bed study for adsorptive removal of furfural by activated carbon. Colloids Surf A: Physicochem Eng Aspects 332:50-56 (2009).

13 Alves LA, Felipe MGA, Silva J, Silva SS and Prata AMR, Pretreatment of sugarcane bagasse hemicellulose hydrolysate for xylitol production by Candida guilliermondii. Appl Biochem Biotechnol 70-2:89-98 (1998).

14 Fargues C, Lewandowski R and Lameloise ML, Evaluation of ionexchange and adsorbent resins for the detoxification of beet distillery effluents. Ind Eng Chem Res 49:9248-9257 (2010).

15 Nilvebrant NO, Reimann A, Larsson S and Jãnsson $L$, Detoxification of lignocellulose hydrolysates with ion-exchange resins. Appl Biochem Biotechnol 91-93:35-49 (2001).

16 Dow. Dowex ion exchange resins, Dowex optipore SD-2 adsorbent as an alternative to activated carbon in the processing of corn syrups and high fructose corn syrups (1998).

17 Larsson S, Reimann A, Nilvebrant NO and Jonsson LJ, Comparison of different methods for the detoxification of lignocellulose hydrolyzates of spruce. Appl Biochem Biotechnol 77-79:91-103 (1999).

18 Schubert J, Bewersdorff J, Luch A and Schulz TG, Waterpipe smoke: a considerable source of human exposure against furanic compounds. Analytica Chimica Acta 709:105-112 (2012).

19 Mazzobre MF, Roman MV, Mourelle AF and Corti HR, Octanol-water partition coefficient of glucose, sucrose, and trehalose. Carbohydr Res 340:1207-1211 (2005).
20 Feng ST, Bagia C and Mpourmpakis G, Determination of proton affinities and acidity constants of sugars.JPhys Chem A 117:5211-5219(2013).

21 Rohm and Haas. Amberlite XAD4, industrial grade polymeric adsorber, product data sheet. (2003).

22 Dow, Product information Dowex Optipore L493 and V493.

23 Lanxess, Product information Lewatit MP 62. (2010).

24 Vertellus, Specifications Reillex HP Polymer.

25 Lanxess, Product information Lewatit Monoplus M 500. (2010).

26 Ramaswamy S, Huang HJ and Ramarao B, Separation and Purification Technologies in Biorefineries. John Wiley \& Sons, 1-36 (2013)..

27 Sing K, The use of nitrogen adsorption for the characterisation of porous materials. Colloids Surf A: Physicochem Eng Aspects 187-188:3-9 (2001).

28 Thomas WJCBD. Adsorption Technology and Design. ButterworthHeinemann, Oxford and Boston (1998).

29 Xu Z, Zhang Q and Fang HHP, Applications of porous resin sorbents in industrial wastewater treatment and resource recovery. Crit Rev Environ Sc Technol 33:363-389 (2003).

30 Sigma Aldrich, Amberlite XAD polymeric resins, product information (1998).

31 Zagorodni AA. Ion Exchange Materials: Properties and Applications. Elsevier, Amsterdam and London (2007).

32 Yan J, Wang $X$ and Chen J, Swelling of porous styrene-divinylbenzene copolymers in water. J Appl Polym Sci 75:536-544 (2000).

33 Millar JR, Smith DG, Marr WE and Kressman TRE, 33. Solvent-modified polymer networks. Part I. The preparation and characterisation of expanded-network and macroporous styrene-divinylbenzene copolymers and their sulphonates. J Chem Soc (Resumed):218-225 (1963).

34 Giles $\mathrm{CH}$, D'Silva AP and Easton IA, A general treatment and classification of the solute adsorption isotherm. Part. Il. Experimental interpretation. J Colloid Interface Sci 47:766-778 (1974).

35 Jerabek K, Hankova L and Prokop Z, Post-crosslinked polymer adsorbents and their properties for separation of furfural from aqueous solutions. Reactive Polymers 23:107-112 (1994).

36 Saari $\mathrm{P}$, Heikkila $\mathrm{H}$ and Hurme $\mathrm{M}$, Adsorption equilibria of arabinose, fructose, galactose, glucose, mannose, rhamnose, sucrose, and xylose on ion-exchange resins. J Chem Eng Data 55:3462-3467 (2010).

37 Khym JX and Zill LP, The separation of sugars by ion exchange. J Am Chem Soc 74:2090-2094 (1952).

38 Saska $M$ and Diack M, Separation of inositols from sugars and sugar alcohols. US patent 5482631. (1996).

39 Spath A and Konig B, Molecular recognition of organic ammonium ions in solution using synthetic receptors. Beilstein J Organic Chem 6:32 (2010)

40 Caruel H, Phemius P, Rigal L and Gaset A, Chromatographic separation of polyols by ligand exchange: effects of the ion-exchange resin cross-linking and size. J Chromatog A 594:125-130 (1992).

41 Vente JA, Bosch $H$, De Haan $A B$ and Bussmann PJT, Comparison of sorption isotherms of mono- and disaccharides relevant to oligosaccharide separations for $\mathrm{Na}, \mathrm{K}$, and Ca loaded cation exchange resins. Chem Eng Commun 192:23-33 (2005).

42 Lei H, Bao Z, Xing H, Yang Y, Ren Q, Zhao M, et al., Adsorption behavior of glucose, xylose, and arabinose on five different cation exchange resins. J Chem Eng Data 55:735-738 (2009).

43 Vankova K, Gramblika M and Polakovic M, Single-component and binary adsorption equilibria of fructooligosaccharides, glucose, fructose, and sucrose on a Ca-form cation exchanger. J Chem Eng Data 55:405-410 (2009).

44 Rohm and Haas. Amberlite XAD polymeric adsorbers (2000). 